\title{
Efeito da energia de soldagem sobre a microestrutura e resistência à corrosão de revestimentos de Inconel 625 aplicados pelo processo GMAW
}

\section{Effect of the arc energy on microstructure and corrosion resistance on Inconel 625 weld overlays deposited by GMAW process}

\author{
Daniel Souza ${ }^{1,2}$, Amanda Figueira Tavares ${ }^{1,3}$, \\ Henara Lillian Costa ${ }^{2,3}$, Alice Gonçalves Osorio ${ }^{2,3}$
}

\footnotetext{
${ }^{1}$ Laboratório de Pesquisa em Engenharia da Soldagem, Escola de Engenharia, Universidade Federal do Rio Grande, Carreiros, Rio Grande do Sul, RS, Brasil.

${ }^{2}$ Programa de Pós-Graduação em Ciência e Engenharia de Materiais, Universidade Federal de Pelotas, Pelotas, Rio Grande do Sul, RS, Brasil. e-mail: danielsouza@furg.br

${ }^{3}$ Programa de Pós-Graduação em Engenharia Mecânica, Universidade Federal do Rio Grande, Carreiros, Rio Grande do Sul, RS, Brasil.

e-mail: amand.figueira@gmail.com, henaracosta@furg.br, osorio.alice@gmail.com
}

\section{RESUMO}

A liga de Inconel 625 é uma superliga à base de níquel altamente resistente à corrosão particularmente utilizada na forme de revestimentos sobre um substrato menos nobre. Existem inúmeras formas de aplicação deste material, sendo uma delas o uso de processos de soldagem. Tradicionalmente faz-se uso de processos de deposição por soldagem que promovam baixa diluição (menor contaminação do Inconel com o material do substrato), mas estes processos possuem característica de baixa produtividade devido às baixas taxas de deposição empregadas. Assim, este estudo tem como objetivo avaliar a aplicação de Inconel 625 utilizando o processo GMAW com diferentes energias de soldagem, que possibilita operar com altas taxas de deposição, mas com o inconveniente de promover alta diluição. Para isso, revestimentos foram depositados com três níveis de energias de soldagem, avaliando seus efeitos sobre a microestrutura e a resistência à corrosão dos depósitos. As macros e microestruturas dos depósitos foram avaliadas por microscopia óptica, microscopia eletrônica de varredura (MEV), espectrometria de energia dispersa (EDS) e difração de raios-X (DRX). Foram medidas a diluição, os espaçamentos dendríticos secundários e avaliadas as microestruturas. A resistência à corrosão dos depósitos foi avaliada por ensaios de polarização potenciodinâmica cíclica. Os resultados mostraram que a relação entre energia de soldagem e diluição dependem da amplitude de tecimento. Observou-se também que a energia de soldagem afetou a quantidade de fases, sendo que energias mais baixas produziram estruturas dendríticas mais refinadas. Além disso, o estudo mostrou que os ensaios de corrosão realizados a temperatura de $25{ }^{\circ} \mathrm{C}$ não promoveram corrosão superficial nas amostras independente da energia de soldagem imposta ao revestimento e que os ensaios a $60^{\circ} \mathrm{C}$ causaram corrosão em todas as condições.

Palavras-chave: Inconel, revestimentos, GMAW, microestrutura, corrosão.

\section{ABSTRACT}

Inconel 625 alloy is a highly corrosion resistant nickel-based alloy, largely used as coatings onto a less noble substrates Many techniques have been used for the deposition of Inconel, including welding processes. Traditionally, welding processes that promote low dilution (less contamination of Inconel with the substrate material) have been used, but they present low productivity due to the low deposition rates involved. Thus, this study aims to evaluate the application of Inconel 625 using the GMAW process under different arc energies, which should lead to high deposition rates, but with the inconvenience of promoting high dilution. For this, coatings were deposited using three levels of arc energies and the effects on microstructure and corrosion resistance were evaluated. The macro and microstructural characteristics of the deposited were evaluated by 
optical microscopy, scanning electron microscopy (SEM), energy-dispersive X-ray spectroscopy (EDS), and $\mathrm{X}$-ray diffraction (XRD). Dilution and secondary dendrite arm spacings were measured and microstructures were evaluated. The corrosion resistance of the deposits was evaluated via cyclic potentiodynamic polarization tests. The results showed that the relationship between arc energy and dilution depended on the weaving amplitude. The arc energy affected the amount of phases, where lower energies produced more refined dendritic structures. In addition, the study showed that corrosion tests conducted at $25^{\circ} \mathrm{C}$ did not promote superficial corrosion in the samples regardless of the arc energy imposed on the coating and that the tests at $60^{\circ} \mathrm{C}$ caused corrosion.

Keywords: Inconel, weld overlay, GMAW, microstructure, corrosion.

\section{INTRODUÇÃO}

O Inconel ${ }^{\circledR} 625$ é uma liga de níquel desenvolvida na década de 50 originalmente projetada para aplicações em turbinas de vapor e gás [1]. É uma superliga de níquel endurecida principalmente pela adição de carbono, cromo, molibdênio e nióbio e foi desenvolvida para serviços a altas temperaturas (abaixo de $1200{ }^{\circ} \mathrm{C}$ ). Esta liga combina excelentes características de fabricação, alta resistência conferida pelo endurecimento por precipitação e grande resistência à corrosão [2].

Devido às suas excelentes características, a aplicação da liga 625 espalhou-se para as indústrias de aeronáutica, naval, química e petroquímica [2]. Outra aplicação desta liga é na produção de revestimentos resistentes à corrosão. A realização dos revestimentos pode ser feita por diversos processos como, por exemplo, soldagem. A deposição por soldagem permite a união físico-química do revestimento ao substrato e a obtenção de um filme espesso de revestimento (da ordem de milímetros). Os processos de soldagem normalmente utilizados para aplicação de revestimentos resistentes à corrosão são aqueles que possuem baixa diluição, de forma a reduzir a "contaminação" do revestimento pelo substrato. Tradicionalmente os processos utilizados são TIG (Tungsten Arc Welding) com alimentação a frio e PTA-P (Plasma Transfered Arc-Powder). Porém, existe também a possibilidade de usar processos com maior diluição, mas que promovam maior capacidade de produção. O processo GMAW (ou MIG/MAG) é um processo com altas taxas de deposição de material devido às suas características de alta densidade de corrente e alimentação contínua de material, o que implica em maior capacidade de produção, mas com diluições superiores às desejadas para os revestimentos em questão.

A resistência à corrosão do Inconel 625 é conferida pela combinação dos seus elementos de liga. O níquel contribui para resistência a muitos meios corrosivos, particularmente em meios redutores, soluções salinas neutras e alcalinas, e é particularmente útil na prevenção de corrosão sob tensão. $\mathrm{O}$ cromo, por outro lado, oferece pouca resistência a meios não oxidantes como ácido clorídrico, mas tem excelente resistência a soluções oxidantes como ácido nítrico. O molibdênio, além da contribuição para resistência mecânica com uma matriz rígida, contribui grandemente para a resistência à corrosão em meios redutores e na promoção da resistência à corrosão por pites [1].

O ensaio mais comumente usado na literatura para avaliação da corrosão no Inconel 625 é o eletroquímico utilizando um potenciostato com três eletrodos. Kim et al. [3] realizaram revestimentos com arame de Inconel 625 variando o calor imposto. Realizando testes de polarização potenciodinâmica em duas soluções: $3,8 \% \mathrm{NaCl}$ e $1 \mathrm{M} \mathrm{HCl}$, concluíram que não houve diferença na resistência à corrosão por pites nas amostras analisadas. Em outro estudo, também depositaram revestimentos com Inconel sobre um substrato de AISI 304L, mas com o processo Laser com adição de arame [4]. Os autores produziram revestimentos com diluição de 4,5 e $12 \%$ e realizaram testes de corrosão de polarização potenciodinâmica com solução de 3,5\% $\mathrm{NaCl}$. Os resultados indicaram que a amostra com menor diluição possui maior resistência à corrosão, contudo em nenhuma amostra foi observada a presença de pites.

Apesar desta liga ter sido inicialmente designada como uma liga endurecida por solução sólida, Eiselstein e Tillack [1] observaram que precipitação de fases intermetálicas ocorreu sob tratamento térmico de envelhecimento nas faixas de temperatura de 1096-1296 ${ }^{\circ} \mathrm{C}$. Segundo Brown e Muzyka [5] o endurecimento por precipitação a elevadas temperaturas é principalmente ocasionado pela fase metaestável $\gamma$ ", $\left[\mathrm{Ni}_{3}(\mathrm{Nb}, \mathrm{Al}, \mathrm{Ti})\right]$. Ainda segundo estes autores, a fase metaestável $\gamma$ " se transforma na fase ortorrômbica $\delta$ $\left[\mathrm{Ni}_{3}(\mathrm{Nb}, \mathrm{Mo})\right]$, sob prolongado envelhecimento. Segundo Kirman [6] a fase $\delta$ também pode ocorrer no envelhecimento da solução sólida supersaturada a temperaturas acima de $1296^{\circ} \mathrm{C}$. Muzyka [7] relata que precipitação de carbetos $\mathrm{M}_{23} \mathrm{C}_{6}, \mathrm{M}_{6} \mathrm{C}$, e $\mathrm{MC}$ ocorreu na faixa de temperaturas de $1306-1556^{\circ} \mathrm{C}$ e que os carbetos $\mathrm{MC}$ presentes no estado não dissolvidos durante o revenimento se decompuseram em $\mathrm{M}_{23} \mathrm{C}_{6}$ e $\mathrm{M}_{6} \mathrm{C}$ sob exposição prolongada a altas temperaturas. Em revestimentos realizados com o processo PTA-P, Antoszczyszyn et al [8] verificaram que os revestimentos apresentaram uma estrutura de solidificação dendrítica. 
Ainda segundo este autor as dendritas são compostas por $\gamma$ (Ni-CFC) rodeadas por uma fase interdendrítica rica em $\mathrm{Nb}-\mathrm{Mo}$ e carbetos do tipo $\mathrm{MC}\left(\mathrm{M}\right.$ : $\mathrm{Nb}$ ou $\mathrm{Mo}$ ) e $\mathrm{Cr}_{23} \mathrm{C}_{6}$. Isto mostra a alta complexidade da microestrutura formada em função da presença de quantidades mesmo que pequenas de $\mathrm{C}$ nos depósitos, decorrente da diluição do substrato e de tratamentos térmicos que podem ocorrer, inclusive durante a soldagem em função do ciclo térmico imposto ao cordão.

Desta forma, o presente estudo tem como objetivo investigar a resistência à corrosão de revestimentos de Inconel 625 aplicados pelo processo MIG/MAG. Apesar da diluição considerável esperada, foi avaliado o efeito da energia de soldagem sobre a diluição, a microestrutura e a resistência à corrosão dos revestimentos, de forma a contribuir para o uso de uma técnica de alta taxa de deposição para a produção de revestimentos de Inconel 625.

\section{MATERIAIS E MÉTODOS}

A metodologia utilizada para alterar a energia de soldagem foi variar a corrente de soldagem e manter a tensão e a velocidade de soldagem constantes. A fonte de soldagem utilizada foi do tipo inversora multiprocesso regulada para se trabalhar no modo MIG/MAG convencional, onde se permite o ajuste da tensão e da velocidade de alimentação de arame $\left(\mathrm{V}_{\text {alim }}\right)$. Assim, para obterem-se as correntes de soldagem, a $\mathrm{V}_{\text {alim }}$ foi ajustada até obterem-se os valores aproximados desejados, que para o estudo proposto foram de 150,200 e 250 A (valores nominais). Para a translação da tocha foi utilizado um braço robótico com seis graus de liberdade que garantiu que os valores da distância bico de contato peça (DBCP) e da velocidade de soldagem $\left(\mathrm{V}_{\text {sold }}\right)$ fossem mantidos constantes durante as soldagens.

Os revestimentos foram confeccionados depositando-se cordões um ao lado do outro em uma única camada. Entre um cordão e outro foi deixada uma distância, doravante chamada de distância entre cordões $\left(\mathrm{D}_{\mathrm{ec}}\right)$, dependente dos parâmetros de corrente e tecimento adotados, medida entre a lateral do último cordão e o centro do cordão a ser feito. Para o substrato foram utilizadas placas de teste de aço comum ao carbono de dimensões $200 \times 150$ × 9,5 mm. O arame-eletrodo utilizado foi da classe AWS ER NiCrMo-3 (Inconel 625) de 1,2 mm de diâmetro. Como gás de proteção foi utilizado $\mathrm{Ar}+25 \% \mathrm{He}$ com vazão de 15 1/min. Durante as soldagens foi utilizada a técnica de tecimento do tipo triangular com frequência de $3 \mathrm{~Hz}$ e amplitude dependente da corrente de soldagem. A dependência da amplitude de tecimento com a corrente foi devido ao aumento de volume de cordão que provocava piora na molhabilidade. Assim, aumentou-se a amplitude de tecimento com o aumento da corrente (volume do cordão). Em todos os testes a DBCP foi ajustada em $17 \mathrm{~mm}$.

Para aquisição dos sinais de corrente e tensão de soldagem foi utilizado um sistema de aquisição de sinais com taxa de $5 \mathrm{kHz}$, calculando a média dos valores de cada cordão de solda. $\mathrm{O}$ valor médio destes parâmetros em cada revestimento foi calculado fazendo-se a média dos valores para todos os cordões formadores do revestimento, obtendo-se, assim, um valor médio de corrente e tensão de soldagem em cada revestimento, conforme Eqs. 1 e 2. Assim, foi calculada uma energia média de soldagem em cada revestimento utilizando-se a Eq. 3.

$$
\begin{aligned}
& U_{r m}=\frac{\sum U_{m}}{n} \\
& I_{r m}=\frac{\sum I_{m}}{n} \\
& E_{S}=\frac{U_{r m} \times I_{r m}}{V_{\text {sold }}}
\end{aligned}
$$

onde $\mathrm{E}_{\mathrm{s}}=$ energia de soldagem média do revestimento $(\mathrm{kJ} / \mathrm{mm}) ; \mathrm{U}_{\mathrm{m}}=$ tensão média de cada cordão (V); $\mathrm{I}_{\mathrm{m}}=$ corrente média de cada cordão $(\mathrm{A}) ; \mathrm{U}_{\mathrm{rm}}=$ tensão média do revestimento $(\mathrm{V}) ; \mathrm{I}_{\mathrm{rm}}=$ corrente média do revestimento (A); n=número de cordões do revestimento; $\mathrm{V}_{\text {sold }}=$ velocidade de soldagem $(\mathrm{mm} / \mathrm{s})$.

Após as soldagens, as placas de teste foram cortadas em uma cortadora metalográfica de modo a expor a seção transversal do cordão de solda. A seção foi lixada com lixas de SiC até a granulometria 600 mesh, polida com alumina $0,5 \mu \mathrm{m}$ e atacada com um ataque eletrolítico com solução aquosa de ácido crômico $10 \% \mathrm{v} / \mathrm{v}$ por $20 \mathrm{~s}$ com uma diferença de potencial imposta de $2,5 \mathrm{~V}$.

A diluição dos cordões, relação entre a área fundida sobre a área total do revestimento, foi medida na 
seção transversal do revestimento utilizando o programa ImageJ. Foram realizadas três medidas de diluição nas seções em diferentes posições da placa revestida. A Figura 1 ilustra o procedimento utilizado para determinação da posição da superfície da chapa tomando como referência a borda inferior. Para determinação da linha que posiciona a superfície da chapa, informação perdida após a deposição dos cordões, uma linha é traçada distante, do valor da espessura da chapa, da borda inferior da chapa.

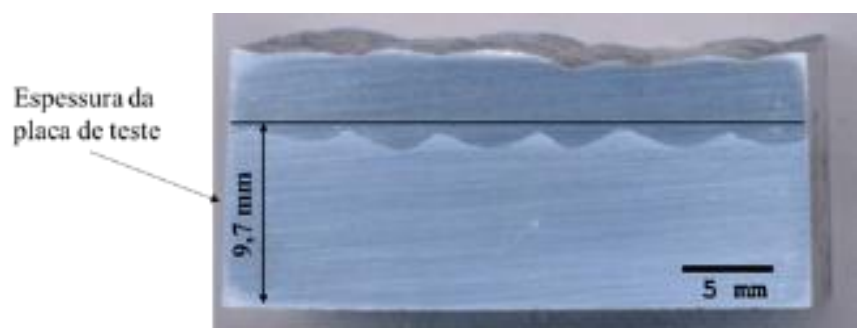

Figura 1: Ilustração do procedimento utilizado para determinação da posição da superfície da chapa utilizando como referência a borda inferior após a deposição do revestimento

Para visualização das fases interdendríticas e medição da composição química das mesmas, foi utilizado um microscópio eletrônico de varredura (MEV) marca JEOL modelo JSM 6610-LV com microssonda de EDS (Energy-Dispersive X-Ray Spectroscopy).

O espaçamento dendrítico secundário foi medido manualmente também por meio do programa ImageJ. Foi utilizado o método D proposto por Vanderluis e Ravindran [9] em seu trabalho. Para medição, foram utilizadas imagens do microscópio óptico e as medições realizadas em quatro regiões da seção transversal do revestimento.

Ensaios de difração de raios-X foram realizados em um difratômetro da marca Bruker modelo D8 Advance para identificar as fases cristalinas presentes nos depósitos, utilizando os seguintes parâmetros: tensão de $40 \mathrm{kV}$, corrente de $40 \mathrm{~mA}$, tubo de cobre, comprimento de onda $(\lambda)$ de 1,5418 , ângulo de varredura de $10^{\circ}$ a $120^{\circ}$ com passo de $0,05^{\circ}$ e tempo de $1 \mathrm{~s}$. As análises foram realizadas utilizando o programa X'Pert HighScore $2.0^{\odot}$.

Para realização dos ensaios de corrosão eletroquímica, a placa de teste soldada foi cortada e usinada para obtenção de um corpo de prova cilíndrico com área de $1 \mathrm{~cm}^{2}$ onde uma das faces era o Inconel. O corpo de prova foi embutido com resina acrílica de modo que somente a face com Inconel ficasse exposta. O corpo de prova foi lixado até a lixa com granulometria 1200 mesh. Foram realizados ensaios de potencial de circuito aberto (OCP - Open Circuit Potential) e ensaio de polarização potenciodinâmica cíclica em uma célula de corrosão com três eletrodos: eletrodo de trabalho (amostra de Inconel 625), eletrodo de referência $(\mathrm{Ag} / \mathrm{AgCl})$ e contra eletrodo $(\mathrm{Pt})$. Como eletrólito foi utilizada uma solução aquosa de $18 \%$ de $\mathrm{NaCl}$ e $0,5 \mathrm{M} \mathrm{H} \mathrm{H}_{2} \mathrm{SO}_{4}$, em duas condições de temperatura: $25^{\circ} \mathrm{C}$ e $60{ }^{\circ} \mathrm{C}$. As temperaturas foram escolhidas para observar o comportamento em uma condição de ensaio a temperatura ambiente e altas temperaturas. $\mathrm{O}$ valor de $60{ }^{\circ} \mathrm{C}$ foi fixado, pois foi observado que para maiores valores de temperatura ocorria algum tipo de reação na solução utilizada que a deixava amarelada. Os ensaios foram realizados a uma taxa de varredura de $0,001 \mathrm{~V} / \mathrm{s}$, tensão inicial de $-0,4 \mathrm{~V}$ e condição de reversão em $1,0 \mathrm{~V}$ ou $5 \mathrm{~mA}$. A solução foi continuamente agitada por meio de um agitador magnético regulado em $100 \mathrm{rpm}$. Os testes foram realizados em triplicata, obteve-se três curvas e plotou-se a curva média. O procedimento foi feito para cada amostra/condição de teste de soldagem e para as duas temperaturas propostas.

\section{RESULTADOS}

\subsection{Soldagem dos revestimentos}

A Tabela 1 mostra os valores regulados/ajustados para os parâmetros e condições de soldagem após realização de testes preliminares. A Tabela 2 mostra os valores da corrente de soldagem em função da velocidade de alimentação para cada revestimento e o respectivo cálculo da energia de soldagem.

Tabela 1: Valores regulados/ajustados para os parâmetros e condições de soldagem.

\begin{tabular}{c|c|c|c|c|c|c}
\hline & $\begin{array}{c}\mathrm{I}_{\text {nom }} \\
(\mathrm{A})\end{array}$ & $\begin{array}{c}\mathrm{Ur} \\
(\mathrm{V})\end{array}$ & $\begin{array}{c}\mathrm{V}_{\text {sold }} \\
(\mathrm{cm} / \mathrm{min})\end{array}$ & $\begin{array}{c}\mathrm{V}_{\mathrm{alim}} \\
(\mathrm{m} / \mathrm{min})\end{array}$ & $\begin{array}{c}\mathrm{A}_{\text {tec }} \\
(\mathrm{mm})\end{array}$ & $\begin{array}{c}\mathrm{D}_{\mathrm{ec}} \\
(\mathrm{mm})\end{array}$ \\
\hline Condição 1 & 150 & 24,0 & 25 & 5,0 & 4 & 1,2 \\
\hline
\end{tabular}




\begin{tabular}{c|c|c|c|c|c|c}
\hline Menor energia & & & & & & \\
\hline $\begin{array}{c}\text { Condição 2 } \\
\text { Energia inter- } \\
\text { mediária }\end{array}$ & 200 & 24,0 & 25 & 7,0 & 6 & 2,5 \\
\hline $\begin{array}{c}\text { Condição 3 } \\
\text { Maior energia }\end{array}$ & 250 & 24,0 & 25 & 11,0 & 8 & 2,5 \\
\hline
\end{tabular}

$I_{\text {nom }}=$ corrente nominal; Ur=tensão de referência $; V_{\text {sold }}=$ velocidade de soldagem; $V_{\text {alim }}=$ velocidade de alimentação; $A_{\text {tec }}=$ Amplitude de tecimento $; D_{e c}=$ distância entre cordões

Tabela 2: Valores médios monitorados de tensão e corrente de soldagem e calculados da energia de soldagem.

\begin{tabular}{|c|c|c|c|c|c|c|}
\hline $\begin{array}{c}\text { Código cor- } \\
\text { dões }\end{array}$ & $\begin{array}{l}\mathrm{U}_{\mathrm{m}} \\
(\mathrm{V})\end{array}$ & $\begin{array}{l}\mathrm{I}_{\mathrm{m}} \\
(\mathrm{A}) \\
\end{array}$ & $\begin{array}{c}\text { Código revesti- } \\
\text { mento }\end{array}$ & $\begin{array}{l}\mathrm{I}_{\mathrm{rm}} \\
(\mathrm{A}) \\
\end{array}$ & $\begin{array}{l}\mathrm{U}_{\mathrm{rm}} \\
(\mathrm{V}) \\
\end{array}$ & $\begin{array}{c}\mathrm{E}_{\mathrm{s}} \\
(\mathrm{kJ} / \mathrm{mm})\end{array}$ \\
\hline 38 & 24,2 & 156 & \multirow{10}{*}{$\begin{array}{c}3847 \\
\text { (condição 1) }\end{array}$} & \multirow{10}{*}{157} & \multirow{10}{*}{24,2} & \multirow{10}{*}{0,913} \\
\hline 39 & 24,2 & 153 & & & & \\
\hline 40 & 24,2 & 156 & & & & \\
\hline 41 & 24,2 & 155 & & & & \\
\hline 42 & 24,2 & 152 & & & & \\
\hline 43 & 24,2 & 159 & & & & \\
\hline 44 & 24,2 & 157 & & & & \\
\hline 45 & 24,2 & 161 & & & & \\
\hline 46 & 24,3 & 162 & & & & \\
\hline 47 & 24,2 & 161 & & & & \\
\hline 19 & 24,2 & 204 & \multirow{7}{*}{$\begin{array}{c}1925 \\
\text { (condição 2) }\end{array}$} & \multirow{7}{*}{207} & \multirow{7}{*}{24,2} & \multirow{7}{*}{1,202} \\
\hline 20 & 24,2 & 213 & & & & \\
\hline 21 & 24,2 & 205 & & & & \\
\hline 22 & 24,2 & 206 & & & & \\
\hline 23 & 24,3 & 205 & & & & \\
\hline 24 & 24,2 & 206 & & & & \\
\hline 25 & 24,2 & 209 & & & & \\
\hline 50 & 24,4 & 260 & \multirow{6}{*}{$\begin{array}{c}5055 \\
\text { (condição 3) }\end{array}$} & \multirow{6}{*}{258} & \multirow{6}{*}{24,4} & \multirow{6}{*}{1,516} \\
\hline 51 & 24,5 & 273 & & & & \\
\hline 52 & 24,5 & 268 & & & & \\
\hline 53 & 24,4 & 251 & & & & \\
\hline 54 & 24,5 & 250 & & & & \\
\hline 55 & 24,4 & 248 & & & & \\
\hline
\end{tabular}

to; $E_{s}=$ energia de soldagem

A Figura 2 apresenta as macrografias de uma amostra da seção transversal e a diluição em função da energia de soldagem imposta aos revestimentos. Pode-se verificar que o aumento da energia de soldagem aplicada, não promoveu um aumento na diluição do revestimento, discordando, a princípio, do comportamento esperado. Entre os testes com energia de soldagem de $0,913 \mathrm{~kJ} / \mathrm{mm}$ e $1,202 \mathrm{~kJ} / \mathrm{mm}$, considerando o desvio padrão, não houve variação na diluição dos revestimentos, mas para a energia de soldagem de $1,516 \mathrm{~kJ}$ ocorreu uma diminuição considerável. 


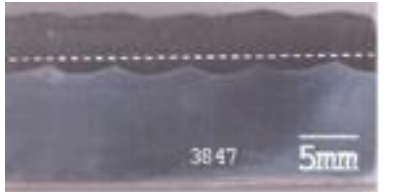

$0,913 \mathrm{~kJ} / \mathrm{mm}$

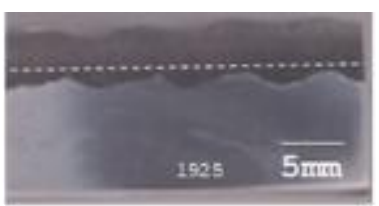

$1,202 \mathrm{~kJ} / \mathrm{mm}$

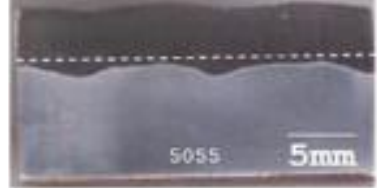

$1,516 \mathrm{~kJ} / \mathrm{mm}$ (a)

Figura 2: Macrografias dos revestimentos (a) e diluição em função da energia de soldagem (b).

\subsection{Microestrutura}

A Figura 3 mostra a macrografia de um trecho da seção transversal da placa revestida e as regiões escolhidas para análise da microestrutura. Podem-se observar regiões mais claras e mais escuras, sendo que as regiões mais claras são regiões de sobreposição dos cordões, enquanto as regiões mais escuras são regiões onde não ocorreu sobreposição. Para análise foram escolhidas quatro regiões que abrangem aproximadamente o centro do cordão e uma região próxima ao topo.

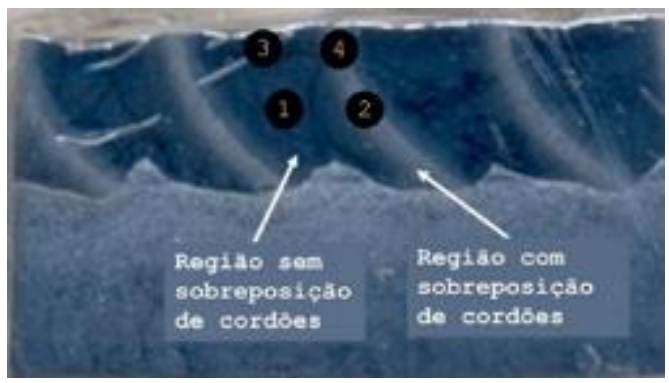

Figura 3: Indicação das regiões do cordão de solda escolhidas para análise.

A Figura 4 mostra as imagens da microestrutura dos revestimentos para cada energia de soldagem resultante. Pode-se observar que a microestrutura apresenta uma morfologia dendrítica com aspectos similares independente da região do cordão e da energia de soldagem aplicada. Desta forma, para uma análise quantitativa da microestrutura, foi realizada a medição do Espaçamento Dentrítico Secundário (SDAS - Secundary Dendritic Arm Spacing), o qual, segundo Vanderluis e Ravindran [9] para materiais com estrutura dendrítica, o SDAS é normalmente caracterizado como a característica microestrutural análoga ao tamanho de grão, ou seja, menores valores de SDAS implicam em maior quantidade de dendritas secundárias por comprimento linear (estrutura mais refinada) o que implica, realizando-se um paralelo com estruturas formadas por grãos, à uma estrutura com maior quantidade de contornos de grão. Desta forma, menores valores de SDAS devem provocar aumento na resistência mecânica do material.

A Figura 5 mostra os valores para o SDAS em função das regiões da seção transversal do revestimento analisadas. Pode-se observar que levando em consideração os desvios padrões dos espaçamentos medidos não há influência da energia de soldagem neste parâmetro. 


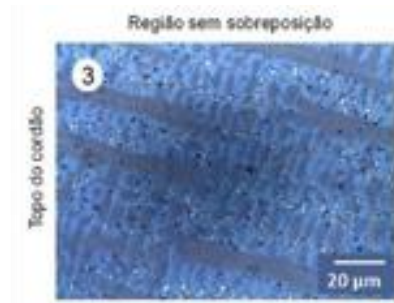

Regiso com sobreposiçlo
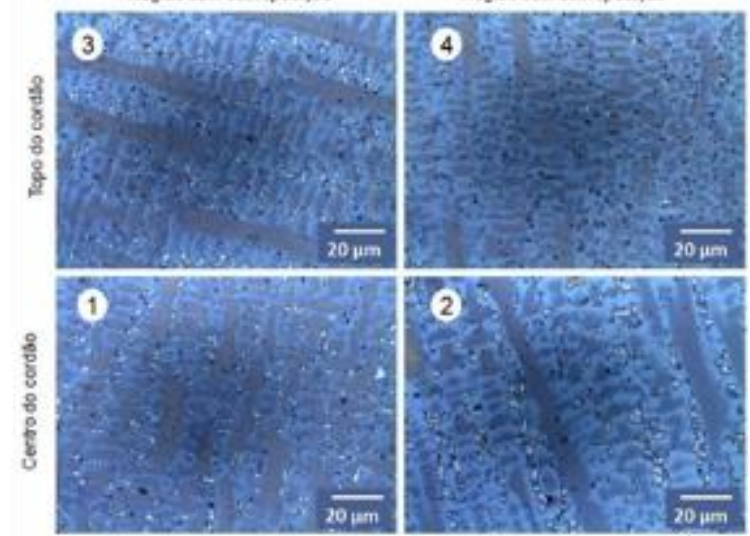

$0,913 \mathrm{~kJ} / \mathrm{mm}$

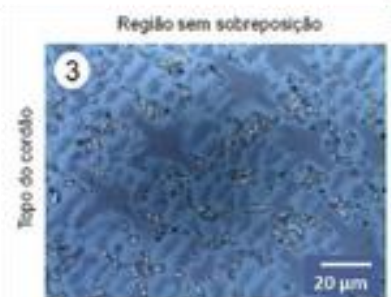

Regilo scom sotreposicho
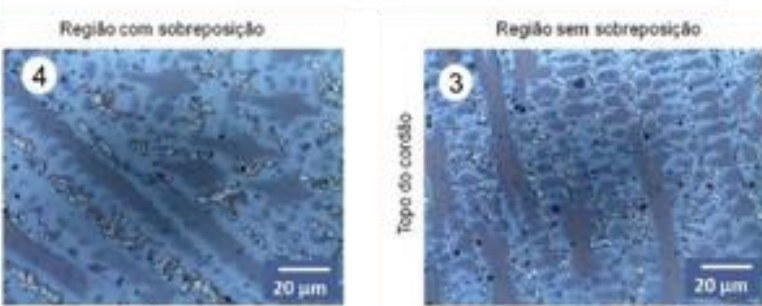

Regbo com sobreposictio
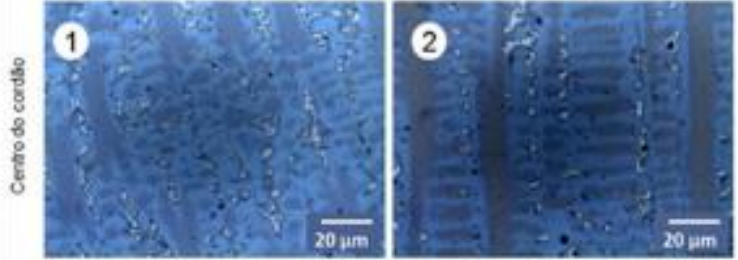

$1,202 \mathrm{~kJ} / \mathrm{mm}$

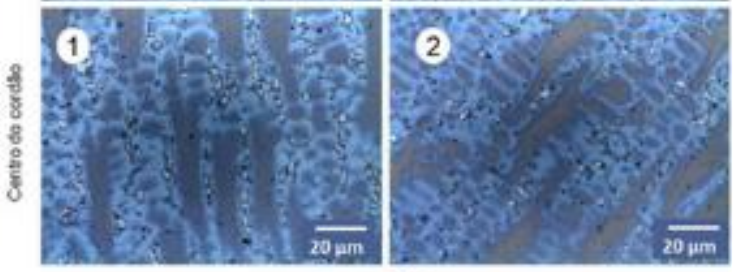

$1,516 \mathrm{~kJ} / \mathrm{mm}$

Figura 4: Macrografias das seções transversais dos revestimentos mostrando as regiões escolhidas para análise.

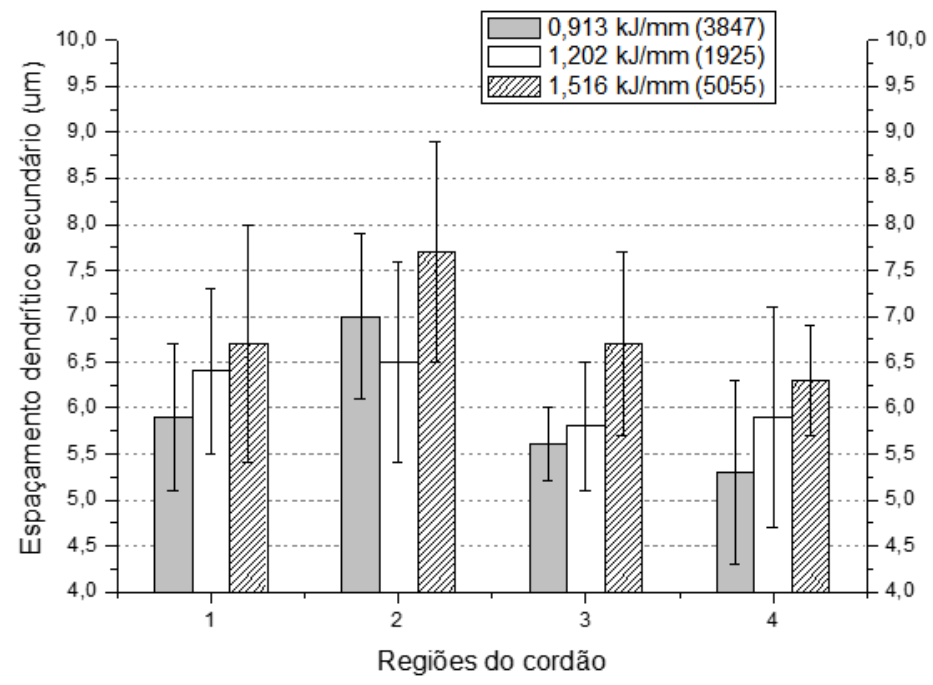

Figura 5: Espaçamento dendrítico secundário para cada região de análise e energia de soldagem.

A Figura 6 apresenta micrografias realizadas usando um microscópio eletrônico de varredura (MEV). Pode-se observar uma matriz dendrítica, uma fase interdendrítica e uma fase clara. Na Figura 7 pode-se observar a composição química de cada uma das regiões medida por EDS. Analisando-se globalmente as fases, verifica-se que as fases dendríticas e interdendríticas apresentam maiores quantidades de $\mathrm{Ni}$ e $\mathrm{Cr}$ quando 
comparadas com as fases mais claras e que as fases claras são mais ricas em $\mathrm{Nb}$ e Mo, sendo este comportamento mais evidenciado para o revestimento com maior energia de soldagem $(1,516 \mathrm{~kJ} / \mathrm{mm})$.

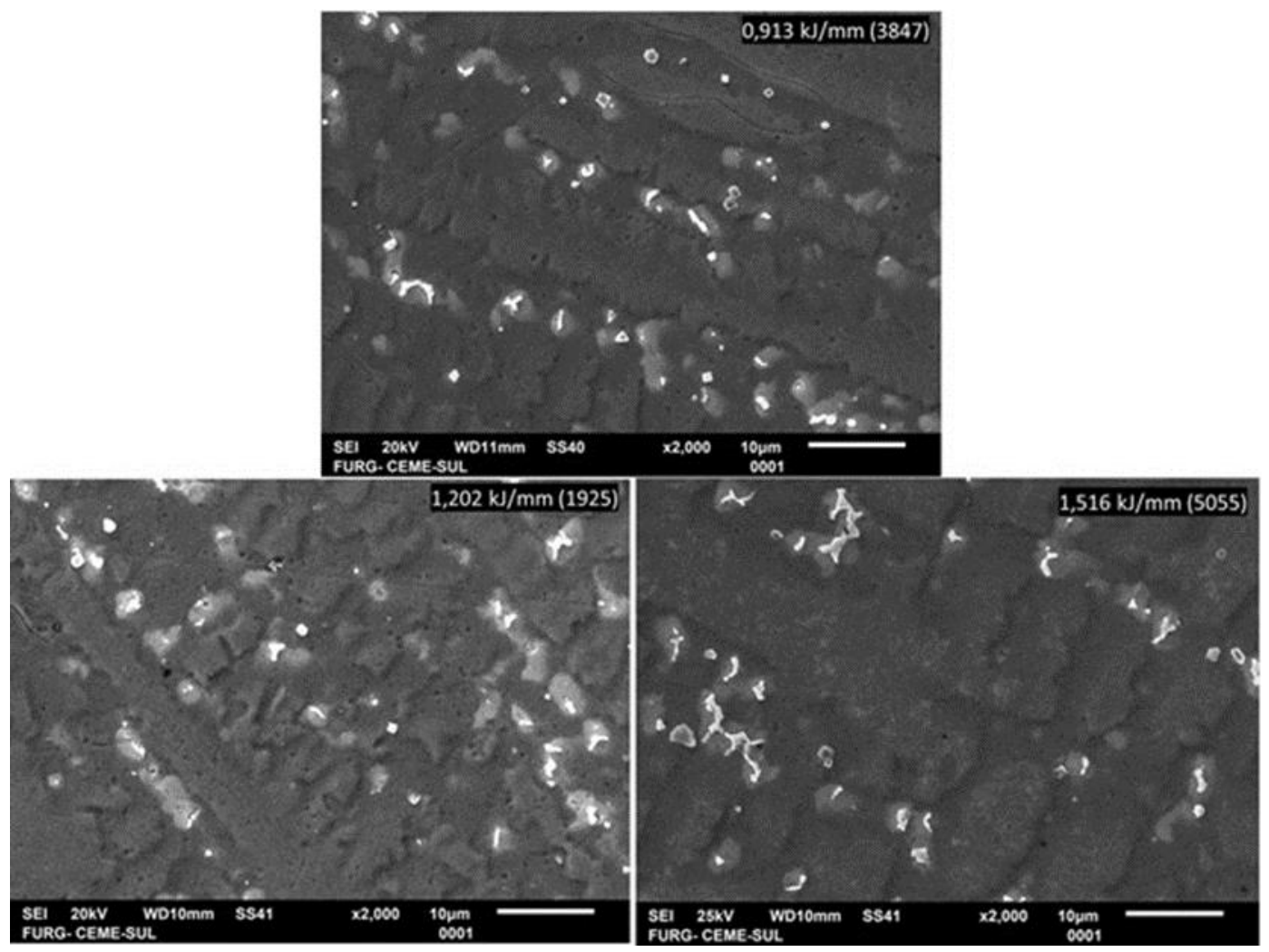

Figura 6: Micrografias (MEV) de regiões próximas do topo da seção transversal dos revestimentos.

A Figura 8 apresenta a análise do difratograma das três amostras de revestimento. A análise dos difratogramas mostra a presença de três fases: $\gamma$-Ni (código ICSD 76667)[10], $\mathrm{Fe}_{3} \mathrm{Ni}_{2}$ (código ICSD 632921)[10] e $\mathrm{Cr}_{23} \mathrm{C}_{6}$ (código ICSD 62667)[10]. Observa-se que a fase $\gamma$-Ni apresenta um deslocamento dos ângulos em relação ao encontrado na base de dados utilizada, mostrado na Tabela 3.

Com base nos difratogramas obtidos, sugere-se que o aumento teórico da taxa de resfriamento (menores valores de energia de soldagem) ocasiona a formação de maior quantidade de carbetos $\mathrm{Cr}_{23} \mathrm{C}_{6}$ (maior intensidade dos picos). 

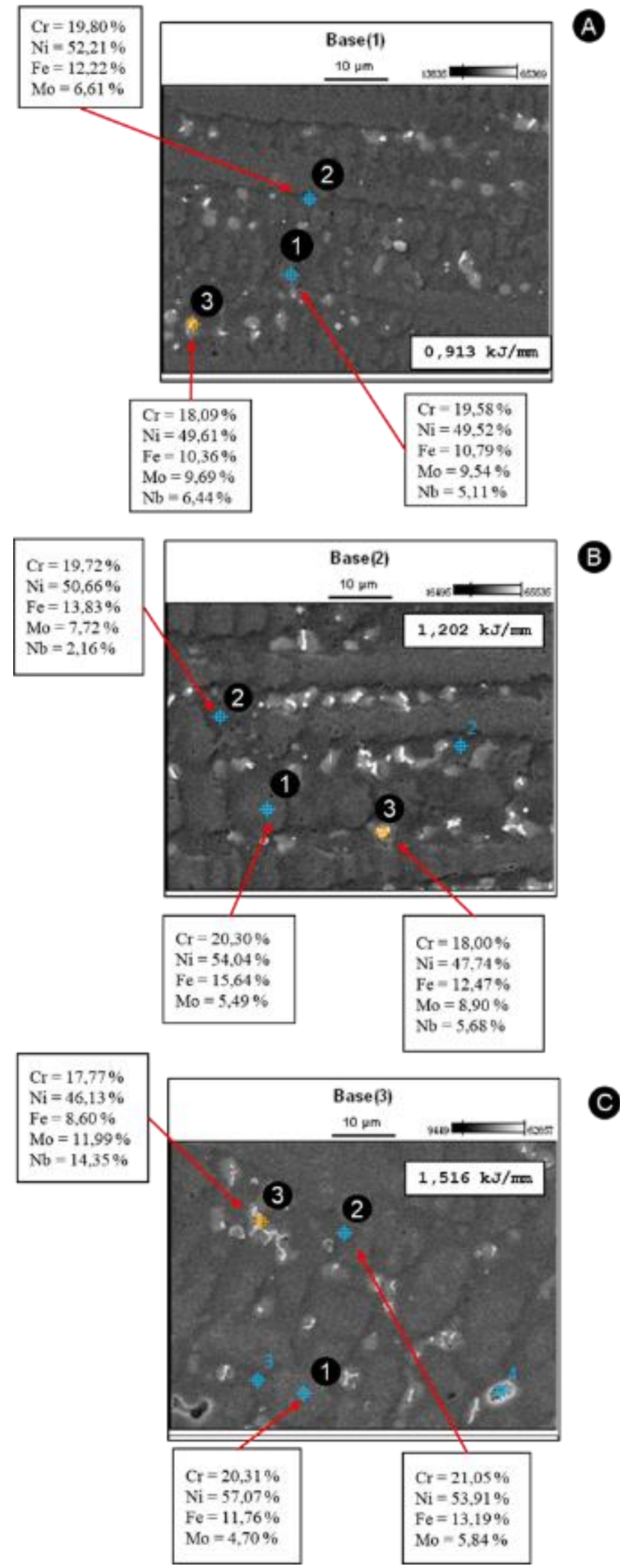

Figura 7: Composição química nos pontos indicados realizada por MEV-EDS para os revestimentos com energias de soldagem de $0,913 \mathrm{~kJ} / \mathrm{mm}$ (A), 1,202 kJ/mm (B) e 1,516 kJ/mm (C). O ponto 1 refere-se a uma região dendrítica, o ponto 2 a uma região interdendrítica e o ponto 3 a uma fase clara (precipitado). 


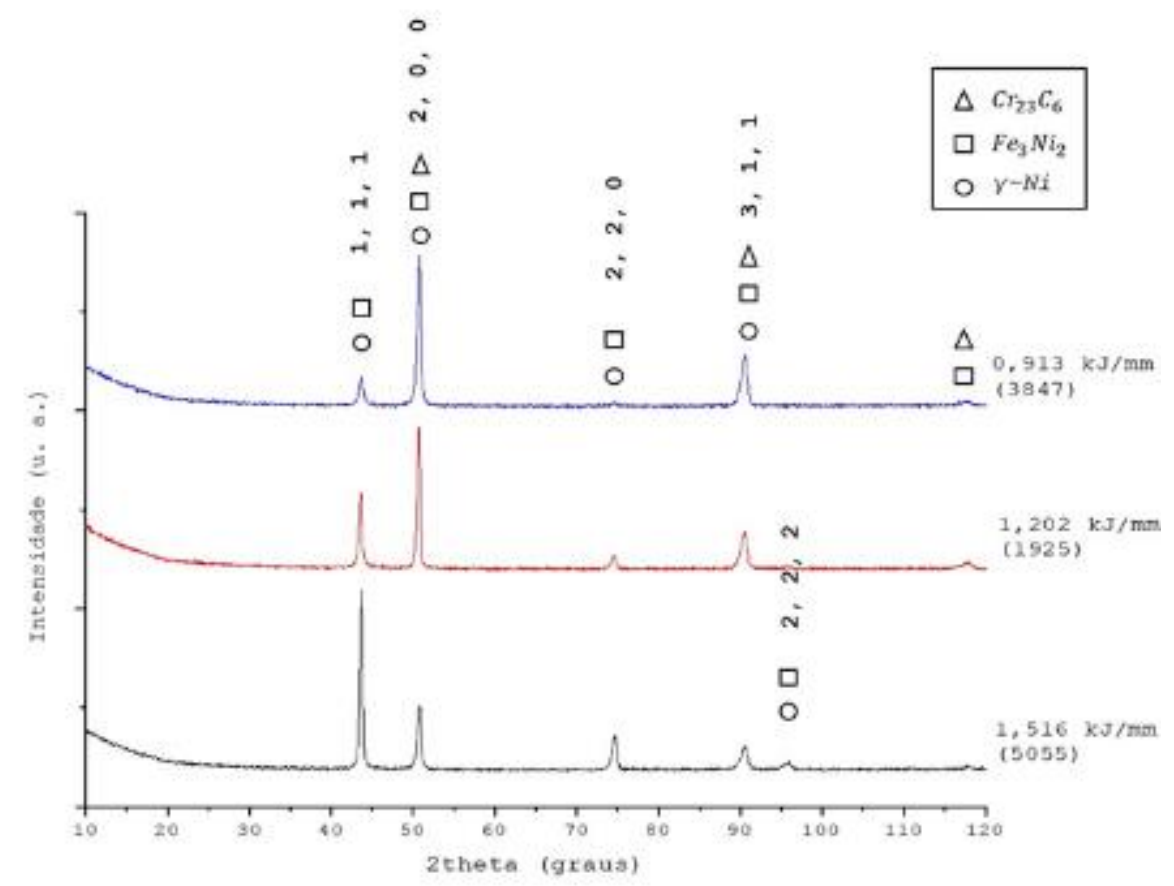

Figura 8: Difratograma dos revestimentos avaliados.

Tabela 3: Comparação dos ângulos dos picos experimental e base de dados para a fase $\gamma$-Ni.

\begin{tabular}{c|c|c|c|c|c}
\hline $\begin{array}{c}\gamma-\mathrm{Ni} \\
(\text { experimental })\end{array}$ & $43,6^{\circ}$ & $50,7^{\circ}$ & $74,7^{\circ}$ & $90,6^{\circ}$ & $95,9^{\circ}$ \\
\hline $\begin{array}{c}\gamma-\mathrm{Ni} \\
(\mathrm{ICSD} 76667)[10]\end{array}$ & $44,5^{\circ}$ & $51,9^{\circ}$ & $76,4^{\circ}$ & $92,9^{\circ}$ & $98,5^{\circ}$ \\
\hline
\end{tabular}

\subsection{Ensaio de corrosão}

As Figuras 9 e 10 apresentam as curvas médias (média das curvas obtidas para três ensaios independentes) resultantes dos ensaios de polarização potenciodinâmica cíclica, nas temperaturas de $25{ }^{\circ} \mathrm{C}$ e $60{ }^{\circ} \mathrm{C}$, respectivamente. A Tabela 4 apresenta os valores de densidade de corrente de passivação em função da energia de soldagem e temperatura. $\mathrm{Na}$ condição de ensaio com temperatura de $25^{\circ} \mathrm{C}$ ocorre uma pequena tendência de aumento abrupto da densidade de corrente nas amostras produzidas com energia de soldagem de 1,202 e $1,516 \mathrm{~kJ} / \mathrm{mm}$, sendo este fenômeno mais pronunciado na amostra com maior energia de soldagem utilizada. Além disto, observa-se, nos ensaios das referidas amostras, a formação de um "laço" após a reversão da polaridade, indicando o fenômeno de repassivação. Também pode-se notar que, na condição de ensaio com temperatura de $25^{\circ} \mathrm{C}$, o aumento da energia de soldagem desloca as curvas no sentido da diminuição da densidade da corrente de corrosão. Para a condição de ensaios realizados a $60{ }^{\circ} \mathrm{C}$ ocorre a tendência contrária, mas menos acentuado do que no caso anterior. Levando-se em consideração o efeito da temperatura, observa-se que os ensaios com temperatura de $60^{\circ} \mathrm{C}$ apresentaram maiores valores de densidade de corrente. 


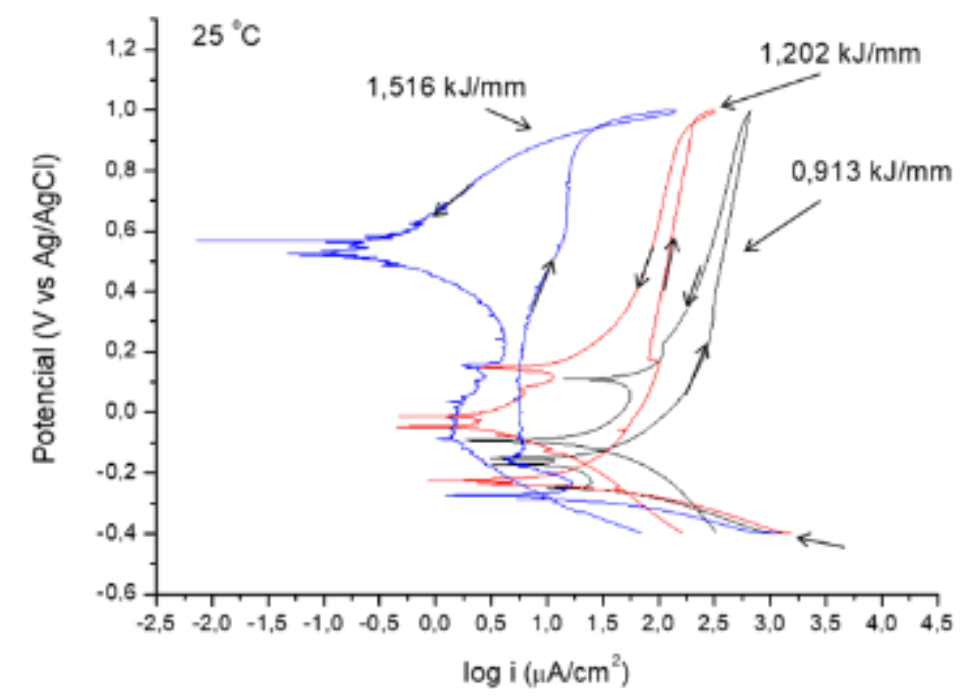

Figura 9: Curvas dos valores médios para os ensaios de polarização potenciodinâmica cíclica a $25^{\circ} \mathrm{C}$.

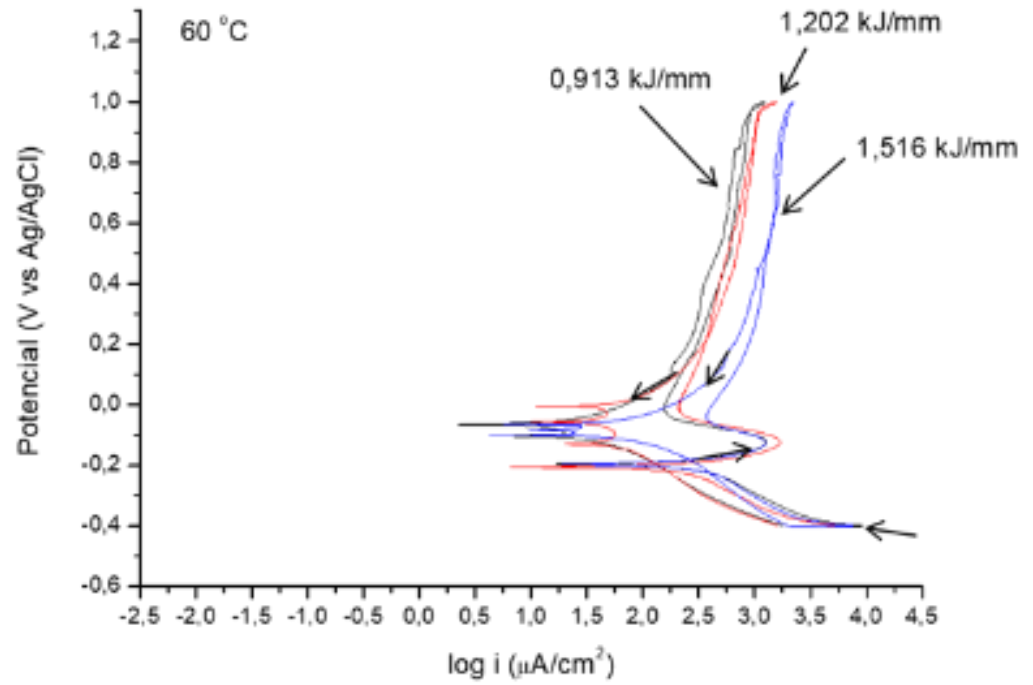

Figura 10: Curvas dos valores médios para os ensaios de polarização potenciodinâmica cíclica a $60{ }^{\circ} \mathrm{C}$.

Tabela 4: Valores de densidade de corrente de passivação em função da energia de soldagem e temperatura do ensaio.

\begin{tabular}{c|c|c}
\hline Temperatura $\left({ }^{\circ} \mathrm{C}\right)$ & Energia de Soldagem $(\mathrm{kJ} / \mathrm{mm})$ & $\mathrm{i}\left(\mu \mathrm{A} / \mathrm{cm}^{2}\right)$ \\
\hline \multirow{3}{*}{25} & 0,913 & $361,95 \pm 41,77$ \\
\cline { 2 - 3 } & 1,202 & $177,10 \pm 32,19$ \\
\cline { 2 - 3 } & 1,516 & $14,04 \pm 0,99$ \\
\hline \multirow{3}{*}{60} & 0,913 & $646,04 \pm 141,33$ \\
\cline { 2 - 3 } & 1,202 & $760,62 \pm 130,48$ \\
\cline { 2 - 3 } & 1,516 & $2041,73 \pm 516,74$ \\
\hline
\end{tabular}




\section{DISCUSSÃO}

\subsection{Soldagem dos revestimentos}

O aumento da energia de soldagem não promoveu o aumento da diluição nos revestimentos (Figura 2). Tal comportamento não é o esperado, pois, com o aumento do calor imposto à peça se esperaria um aumento na diluição. Porém, levando-se em consideração o uso do tecimento, neste caso diferente para cada condição, pode se atribuir o resultado não esperado à diferença na dimensão da área de aplicação do calor no substrato (justamente devido ao tecimento). Assim, para explicar especificamente o resultado da diluição, propõe-se o cálculo da energia de soldagem em função da dimensão da área de atuação do arco elétrico (área de distribuição de calor). Para isto, divide-se a energia de soldagem linear pela amplitude do tecimento (Tabela 1) resultando em um valor de energia de soldagem em função da área de distribuição do calor (energia de soldagem específica). Desta forma, os valores da energia de soldagem por área e respectivos valores de diluição são apresentados na Figura 12. Observa-se que para o menor valor de energia de soldagem específica tem-se o menor valor de diluição, mas para o valor intermediário e para o maior valor de energia não se observa variação na diluição.

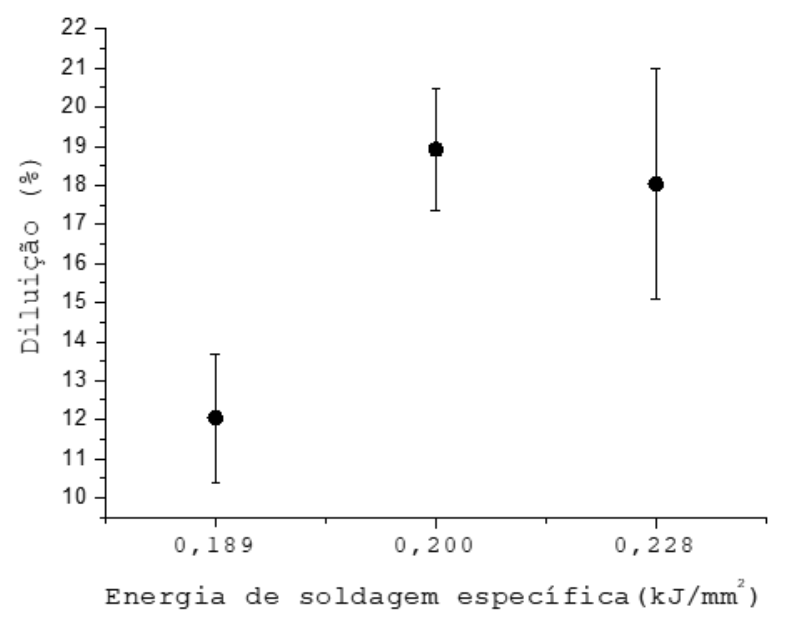

Figura 11: Valores de diluição em função da energia de soldagem específica.

\subsection{Microestrutura}

A imagens da microestrutura apresentada na Figura 6 mostram uma estrutura dendrítica e interdendrítica muito similar à encontrada por outros autores que estudaram o Inconel 625 [3, 4, 8, 11, 12]. Todos estes autores apresentaram imagens e identificaram as regiões mais claras entre as dendríticas como carbetos do tipo MC e fase Laves. Porém, no presente estudo estas fases não foram identificadas na análise de DRX.

O espaçamento dendrítico secundário apresentou uma tendência de refino da microestrutura para menores energias de soldagem. Apesar da energia de soldagem modificar a diluição, o efeito sobre o refino da microestrutura deve estar ligado à alteração na taxa de resfriamento; quanto menor a energia de soldagem, maior a taxa de resfriamento e mais refinada fica a microestrutura. Esta hipótese está em concordância com estudos realizados por Antonsson e Fredriksson [15] e Patel e Murty [16] em lingotes de Inconel 718 (liga similar ao Inconel 625).

Antoszczyszyn et al [8] mostraram difratogramas de um estudo com revestimentos de Inconel 625 aplicados por PTA. As estruturas identificadas por este autor são compatíveis com as encontradas no presente trabalho. Porém, no presente estudo não foi identificado o carbeto MC, indicado pelo autor nos seus difratogramas. Li et al [17] realizaram um estudo onde foram produzidas amostras por meio de Selective Laser Melting (técnica de manufatura aditiva) usando pó de Inconel 625 e realizou tratamento térmico de recozimento com diferentes temperaturas. Os difratogramas obtidos corroboram os resultados do presente estudo. Pode-se observar que os ângulos e as intensidades em que os picos ocorrem são compatíveis com os encontrados nos difratogramas deste estudo. Portanto, chama-se a atenção para indicação do carbeto MC identificado pelo autor na posição $2 \theta \approx 43^{\circ}$ que não foi encontrado durante a análise realizada neste estudo.

Em um trabalho usando Laser com adição de arame Abioye et al. [4] realizaram revestimentos de Inconel 625 sobre um substrato de AISI 304. Analisando o difratograma obtido por estes autores, o mesmo 
também verifica um deslocamento dos ângulos do difratograma em relação ao banco de dados utilizado, fenômeno muito similar ao ocorrido neste estudo (Tabela 3). Abioye et al [4] citam que esta diferença é devida aos elementos em solução sólida no Inconel 625, pois, isto afeta os espaços interplanares da matriz $\gamma$-Ni no revestimento. Este mesmo autor afirma não ter encontrado outras fases além da $\gamma-\mathrm{Ni}$ devido, ainda segundo o autor, ao limite de detecção por DRX de fases secundárias ser de aproximadamente de 1 a $2 \%$, o que pode explicar a ausência de identificação de fases como Laves e MC nos difratogramas do presente estudo.

$\mathrm{O}$ aumento da formação da fase $\mathrm{Cr}_{23} \mathrm{C}_{6}$ observada no difratograma (Figura 8), por hipótese pode ser devido ao aumento da diluição e consequente aumento da porcentagem de $\mathrm{C}$, mas também ao aumento da taxa de resfriamento.

\subsection{Ensaio de corrosão}

A análise das curvas potenciodinâmicas para $25^{\circ} \mathrm{C}$ (Figura 9), mostram o revestimento com maior energia de soldagem $(1,516 \mathrm{~kJ} / \mathrm{mm})$ apresenta maior resistência à corrosão, curva com menores valores de densidade de corrosão. Além disso, neste ensaio, observa-se, pela Tabela 4, que o aumento da energia de soldagem aumentou a resistência à corrosão (verificado pelos menores valores de densidade de corrente de passivação). Como já visto anteriormente para menores valores de energia de soldagem há um aumento na quantidade $\operatorname{de} \mathrm{Cr}_{23} \mathrm{C}_{6}$. Guo el al [14], em um estudo com revestimentos soldados submetidos a tratamento térmico pós soldagem a diferentes temperaturas, citam que elementos como $\mathrm{Cr}$, $\mathrm{Nb}$ e Mo se difundem dos núcleos dendríticos para as regiões interdendríticas, aumentando as chances de fases precipitadas nestas regiões. No caso do presente estudo, a maior quantidade de $\mathrm{Cr}_{23} \mathrm{C}_{6}$ no revestimento aplicado com menor energia de soldagem pode ser devido à maior diluição. Sabe-se que o aumento do precipitado, devido à segregação, vai empobrecer a matriz pela diminuição do elemento formador do mesmo, no caso, a matriz de Ni fica empobrecida de Cr. Os resultados mostraram que o pior resultado de resistência à corrosão foi da amostra de revestimento com maior quantidade de carbetos $\mathrm{Cr}_{23} \mathrm{C}_{6}$ (3847). Alguns autores apresentaram resultados semelhantes em seus estudos $[4,11,14]$, os quais foram atribuídos à ocorrência de uma forma de acoplamento galvânico onde a matriz funciona como eletrodo de sacrifício.

As curvas dos ensaios realizados a $25^{\circ} \mathrm{C}$ mostram uma diferença na resistência à corrosão devido às diferenças nas densidades de corrente apresentadas. Foi observado o aumento abrupto da densidade de corrente nas amostras produzidas com energia de soldagem de 1,202 e 1,516 kJ/mm e a formação de um "laço" durante a reversão, que indica a repassivação do material, fenômeno este não observado para a amostra revestida com energia de soldagem de $0,913 \mathrm{~kJ} / \mathrm{mm}$ (menor valor de energia utilizado). A repassivação mostrada nas curvas, indica teoricamente a ocorrência de corrosão e sua repassivação devido à reversão do potencial. Apesar destas indicações de corrosão, a Figura 12 mostra que em nenhuma das amostras pós corrosão pode se observar sinais de corrosão generalizada, por pites ou fretas. Outros estudos, também com revestimentos de Inconel 625 aplicados por processos de soldagem com variados valores de diluição e energias de soldagem, apresentaram resultados pós corrosão que vão ao encontro dos resultados apresentados no presente estudo [3, 4, 11, 14]. Porém, a inobservância de corrosão superficial nas amostras supracitadas do presente estudo, não permite concluir que não há corrosão nestas amostras. Neste caso, amparada pelos resultados observados nas curvas de corrosão, pode-se levantar a hipótese da ocorrência de corrosão interdendrítica.

Já para condição de ensaio a $60^{\circ} \mathrm{C}$, as curvas estão verticalmente mais próximas e, no geral, com maiores valores de densidade de corrente quando comparadas com a condição de ensaio a $25^{\circ} \mathrm{C}$ (Figura 9 x Figura 10). Isto sugere que, na condição a $60^{\circ} \mathrm{C}$, a energia de soldagem tem menor efeito sobre a resistência à corrosão e que a temperatura aplicada ao ensaio diminuiu a resistência à corrosão dos revestimentos. Esta afirmação pode ser reforçada pela análise da superfície das amostras pós corrosão (Figura 13). Nesta figura, observa-se a existência de regiões com corrosão por frestas (indicadas por setas nas imagens). Também se observa, nas curvas de corrosão para temperatura de $60{ }^{\circ} \mathrm{C}$, que não ocorre a repassivação do material. Como foram observadas corrosão por frestas nestas amostras, isto indica que nesta temperatura e sob as condições de corrosão impostas, o material não apresentou capacidade de repassivação. 

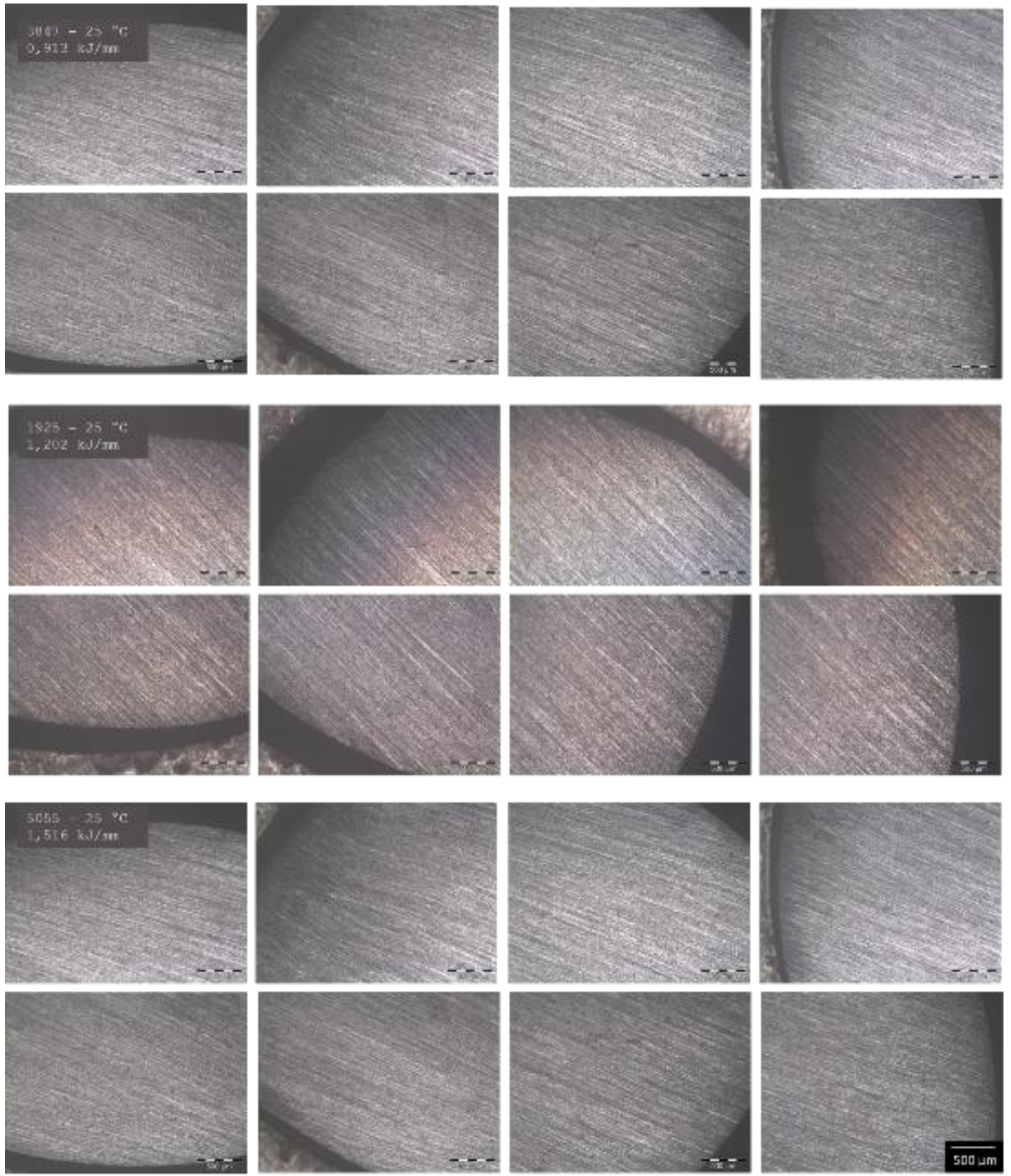

Figura 12: Imagens de microscópio óptico da superfície das amostras dos revestimentos submetidas à corrosão a $25^{\circ} \mathrm{C}$. As amostras possuem uma superfície circular, mas para melhor visualização da superfície foram realizadas oito imagens que juntas compõem toda a área superficial da amostra. 

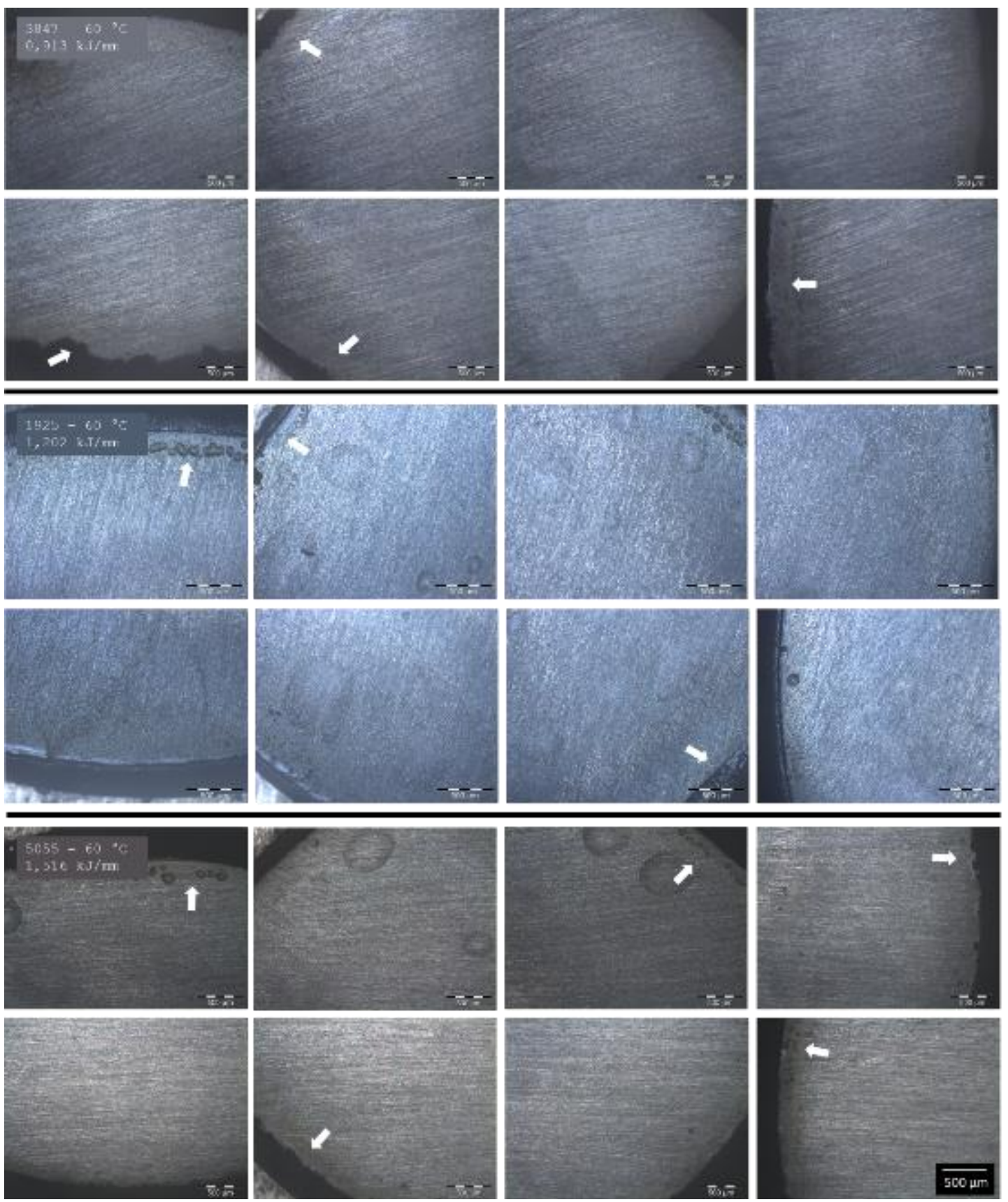

Figura 13: Imagens de microscópio óptico da superfície das amostras dos revestimentos submetidas à corrosão a $60^{\circ} \mathrm{C}$, as setas indicam regiões de corrosão por frestas. As amostras possuem uma superfície circular, mas para melhor visualização da superfície foram realizadas oito imagens que juntas compõem toda a área superficial da amostra.

De modo geral, os revestimentos aplicados por GMAW, apesar de caracteristicamente apresentarem maiores valores de diluição, mostraram microestruturas visualmente similares e com composição química e de fases compatíveis com revestimentos de Inconel 625 aplicados por processos que apresentam menores valores de diluição. Porém, quando análise da microestrutura é realizada comparativamente à energia de soldagem aplicada, verificou-se variações na estrutura do revestimento. Já os ensaios de corrosão mostraram que a energia de soldagem só influenciou de maneira considerável a resistência à corrosão à temperatura ambiente e que a temperatura do ensaio é um parâmetro importante na avaliação de revestimentos de Inconel 625. A energia de soldagem, exceto para a resistência à corrosão à temperatura ambiente, não se mostrou um fator de degradação da estrutura do material em questão, mas tem a vantagem de, para maiores valores, proporcionar maior capacidade de produção. 


\section{CONCLUSÕES}

Para os parâmetros, condições e materiais utilizados neste estudo, pode-se concluir que:

Nem sempre o aumento da energia de soldagem promove um aumento na diluição quando a técnica de tecimento é utilizada, neste caso deve-se relacionar a diluição à energia específica (energia por área);

Nos revestimentos foram identificadas as fases $\gamma-\mathrm{Ni}, \mathrm{Cr}_{23} \mathrm{C}_{6}$ e $\mathrm{Fe}_{3} \mathrm{Ni}_{2}$ pela análise dos difratogramas. Foi identificado que as fases $\gamma-\mathrm{Ni}, \mathrm{Cr}_{23} \mathrm{C}_{6}$ e $\mathrm{Fe}_{3} \mathrm{Ni}_{2}$ têm a sua quantidade nos revestimentos dependente da energia de soldagem utilizada;

Os testes de corrosão realizados a temperatura de $25{ }^{\circ} \mathrm{C}$ mostraram que o aumento da energia de soldagem aplicada ao revestimento aumentou a resistência à corrosão do mesmo, apesar das amostras não apresentarem corrosão visível na superfície;

Já os testes de corrosão realizados à temperatura de $60^{\circ} \mathrm{C}$ mostraram que a energia de soldagem tem pouca influência sobre a resistência à corrosão, entretanto, nesta temperatura os revestimentos apresentaram menor resistência à corrosão do que na temperatura de $25^{\circ} \mathrm{C}$.

\section{AGRADECIMENTOS}

Os autores do presente estudo gostariam de agradecer ao LaPES/FURG (Laboratório de Pesquisa em Engenharia da Soldagem da Universidade Federal do Rio Grande) pela disponibilização da infraestrutura laboratorial e consumíveis utilizados. Também são gratos ao CEME-SUL (Centro de Microscopia Eletrônica do Sul da Universidade Federal do Rio Grande) pela realização dos ensaios no Microscópio Eletrônico de Varredura e no Difratômetro de Raios-X.

\section{BIBLIOGRAFIA}

[1] EISELSTEIN, H. L., TILLACK, D. J., The invention and definition of alloy 625, The Minerals, Metals and Materials Society,1991.

[2] SHANKAR, V., RAO, K. B. S., MANNAN, S. L., "Microstructure and mechanical properties of Inconel 625 superalloy”, Journal of Nuclear Materials, n. 288, pp. 222-232, 2001.

[3] KIM, J. S., PARK, Y. I., LEE, H. W., "Effects of heat input on the pitting resistance of Inconel 625 welds by overlay welding", Metals and Materials International, v. 21, n. 2, pp. 350-355, 2015.

[4] ABIOYE, T. E., MCCARTNEY, D. G., CLARE, A. T., "Laser cladding of Inconel 625 wire for corrosion protection”, Journal of Materials Processing Technology, n. 217, pp. 232-240, 2015.

[5] BROWN, E. E., MUZYKA, D. R., The Superalloys II, New York, John Wiley, 1987.

[6] KIRMAN, I, "Precipitation in the Fe-Ni-Cr-Nb system", Journal of the Iron and Steel Institute, v. 207, pp. $1612-1618,1969$.

[7] MUZYKA, D. R., The Superalloys, New York, John Wiley, 1972.

[8] ANTOSZCZYSZYN, T. J., PAES, R. M. G., OLIVEIRA, A. S. C. M., et al.,"Microstructure and properties of Ni-based 625 alloy coatings by plasma transferred arc (PTA) on different steel substrate, CT-19, Curitiba, PR, Brasil, 25-28 Novembro 2015.

[9] VANDERLUIS, E., RAVINDRAN, C., "Comparison of Measurement Methods for Secondary Dendrite Arm Spacing”, Metallography, Microstructure, and Analysis, n. 6, pp. 89-94, 2017.

[10] FIZ-KARLSRUHE, https://icsd.fiz-karlsruhe.de/search/basic.xhtml. Acessado em fevereiro de 2019.

[11] AHMED, N., BAKARE, M. S., MACCARTENY, D. G., et al., "The effects of microstructural features on the performance gap in corrosion resistance between bulk and HVOF sprayed Inconel 625", Surface and Coatings Technology, v. 204, pp. 2294-2301, 2010.

[12] XU, F., LV, Y., LIU, Y., et al., "Microstructural evolution and mechanical properties of Inconel 625 alloy during pulsed plasma arc deposition process", Journal Materia Science Technology, v. 25, n. 5, pp. 480-488, 2013.

[13] SOLECKA, M., KOPIA, A., RADZISZEWSKA, A., et al., "Microstructure, microsegregation and nanohardness of CMT clad layers of Ni-base ally on 16Mo3 steel", Journal of Alloys and Compounds, v. 751, pp. 86-95, 2018. 
[14] GUO, L., ZHENG, H., LIU, S., et al., "Effect of heat treatment temperatures on microstructure and corrosion properties of Inconel 625 weld overlay deposited by PTIG”, International Journal of Electrochemical Science, v. 11, pp. 5507-5519, 2016.

[15] ANTONSSON, T., FREDRIKSSON, H., "The effect of cooling rate on the solidification of Inconel 718”, Metallurgical and Materials Transactions B, v. 36B, pp. 85-96, Feb. 2005.

[16] PATEL, A. D., MURTY, Y. V., Effect of cooling rate on microstructural development in alloy 718, The Minerals, Metals and Materials Society,2001.

[17] LI, S., WEI, Q., SHI, Y., et al., "Microstructure characteristics of Inconel 625 superalloy manufactured by Selective Laser Melting”, Journal of Materials Science and Technology, v. 31, pp. 946-952, 2015.

\section{ORCID}

Daniel Souza

Amanda Figueira Tavares

Henara Lillian Costa

Alice Gonçalves Osorio
https://orcid.org/0000-0003-2884-227X

https://orcid.org/0000-0001-7618-6217

https://orcid.org/0000-0002-0412-4436

https://orcid.org/0000-0002-1825-3749 